\title{
DEVELOPMENT OF ISOTHERMALLY FORGED P/M UDIMET 720 FOR TURBINE DISK APPLICATIONS
}

\author{
Kenneth A. Green \\ Allison Engine Company \\ Joseph A. Lemsky \\ Ladish Co., Inc. \\ Robert M. Gasior \\ Dynamet Powder Products
}

\begin{abstract}
Udimet $720^{\left(\Theta^{*}\right.}$ nickel-base superalloy is in current use as the material for the stage-two power turbine disk for the T800 engine. This alloy was selected because of its attractive level of tensile strength and resistance to low cycle fatigue (LCF). Advancements in novel isothermal forging technology have enabled the production of romplex disk forgings called cluster forgings. A single cluster forging produces seven PT2 disks in a single forging operation. Coupled with recent advances in powder metallurgy $(\mathrm{P} / \mathrm{M})$ billet production featuring consolidation by HIP followed by extrusion, turbine disk forgings can be produced at a significant cost reduction as compared to single-piece hot die forged disks made from conventional cast/wrought billet. $\mathrm{P} / \mathrm{M}$ Udimet 720 material displays excellent mechanical properties, competitive with other high strength disk alloys. Turbine disks produced from isothermally forged $\mathrm{P} / \mathrm{M}$ Udimet 720 passed component test requirements established for the T800 engine. A significant cost reduction resulted from the use of this process.
\end{abstract}

\section{Introduction}

Udimet 720 is a high strength nickel-base superalloy currently in use as a turbine disk material. Udimet 720 is a relatively new disk alloy, having been developed originally as a wrought turbine blade alloy for industrial turbine applications (Ref. 1). More recently, Udimet 720 has been recognized as having outstanding strength and fatigue resistance when used in a fine grain form for turbine disk applications. From a mechanical property standpoint the alloy retains the high strength characteristics of alloys such as $\mathrm{P} / \mathrm{M}$ alloy Rene 95, but has superior crack growth characteristics (Ref. 2). Overall, Udimet 720 has the best combination of mechanical properties in its class of high strength cast/wrought disk alloys and is used in a variety of applications in small- to medium-sized gas turbine engines.

Udimet 720 alloy in the cast/wrought form is in current use as the turbine disk alloy for all four stages of the T800 turboshaft engine currently being developed by the U.S. Army. The T800 engine is the powerplant for the Army's RAH-66 Comanche helicopter. When fielded, this aircraft system will represent the current state-of-the-art in its class, with the most advanced air vehicle, avionics, propulsion, and weapons systems available. Udimel 720 was selected for this application because of its high tensile strength characteristics as well as its resistance to LCF. Currently, the disks are produced as singlepiece hot die forgings from 4.5 in. diameter cast/wrought billet.

\footnotetext{
* Udimet is a registered trademark of Special Metals Corporation. Superalloys 1996 Edited by R. D. Kissinger, D. J. Deye, D. L. Anton,

In support of affordability goals, an effort was undertaken to implement lower cost disks in the stage-two power turbine (PT2) of the $T 800$. Cost reduction was achieved by utilizing a recently developed isothermal forging process called cluster forging in which multiple disks are produced in a single large forging. In this application, a single cluster forging produces seven PT2 disks. Because multiple disks are produced in a single pressing operation, material utilization is improved and overall costs are reduced significantly. The high weight (nearly $300 \mathrm{lb}$ ) of the cluster forging requires a relatively large starting billet of 9.0 in. diameter. However, conventional cast/wrought Udimet 720 billet is difficult to produce economically in this size. To provide a cost-effective option to the billof-material, a $\mathrm{P} / \mathrm{M}$ approach was utilized to produce uniform large diameter forging billet. Coupled with the cluster forging concept, the PT2 disk can be produced in a very cost-effective manner.

\section{Material}

\section{Background}

The composition of Udimet 720 has evolved over a period of several years from a wrought turbine blade alloy to high strength turbine disk applications. Udimet 720 is the most highly alloyed disk material currently being produced by the cast/wrought route. Current ingot manufacturing practice involves triple melting (VIM/ESR/VAR) followed by conversion to billet by a series of homogenization, upsetting, and cogging cycles. Conventional cast/wrought Udimet 720 billet is difficult to produce in the size required for cluster forgings because of yield losses that occur due to the alloy's propensity to crack during the billet manufacturing cycle. Microstructural variation caused by inherent solidification segregation in the cast ingot may persist in the eventual billet (Ref. 3). As a result, much effort has been given to the alloy's ability to be manufactured consistently and with high yield into large diameter billet. To control the propensity for segregation and formation of unwanted phases such as carbide- and boride-rich stringers, the composition has been adjusted to meet the strict quality and property requirements. In particular, levels of carbon, boron and chromium have been lowered from the original composition to address the various segregation, alloy stability and billet yield issues.

\section{Composition Selection}

In selecting the composition for $\mathrm{P} / \mathrm{M}$ Udimet 720 , Table I, careful consideration was given to factors that determine cost and performance. It was desirable to keep the alloying variables (carbon, boron and chromium) near the levels in current use cast/wrought Udimet 
$720 \mathrm{MC}$, which is the composition currently in use at Allison for turbine disk applications. The composition for $\mathrm{P} / \mathrm{M}$ moderates the levels of carbon $(0.025 \mathrm{wt} . \%)$ and boron $(0.020 \mathrm{wt} . \%)$ with respect to Udimet $720 \mathrm{MC}$. Raising carbon and boron takes advantage of the high temperature strengthening contributions attributed to those elements. Chromium for the $\mathrm{P} / \mathrm{M}$ version was maintained at the same level $16.0 \mathrm{wt} . \%$ as Udimet $720 \mathrm{MC}$. The $\mathrm{P} / \mathrm{M}$ composition selected for this effort is also being evaluated by other engine manufacturers and offers the potential for universal acceptance which should ultimately have a favorable impact on cost due to commonality of specifications.

\section{P/M Billet Processing}

The billet production process, as shown in Figure 1, utilized in this effort by Dynamet Powder Products featured consolidation of powder by hot isostatic press (HIP) followed by extrusion into 9 inch diameter forging billet. The benefits of an extruded $\mathrm{P} / \mathrm{M}$ billet are well documented with respect to minimizing the effects of nonmetallic inclusions and other defects (Ref. 4). The combination of HIP and extrude enhances microstructural uniformity and forgeability in a very cost-effective manner. By consolidation to full density during HIP, the need for high extrusion ratios commonly employed for hot compacted powder billet was avoided. This creates a more favorable situation with respect to the available supplier base for large diameter extrusions.

\section{Powder Processing}

Udimet 720 powder was produced by Dynamet via argon atomization of vacuum induction melted virgin material. The powder was screened to a -150 mesh. The powder particle distribution size exhibited a high percentage of fines, which were measured in excess of $50 \%-325$ mesh. Water elutriation test results from the powder master blend totaled approximately 6.0 particles (1.6 hard, 3.6 friable and 0.8 soft) per pound of powder, indicating a very clean blend of powder.

\section{HIP Consolidation}

HIPed billet preforms were made by filling 20 in. diameter stainless steel cans with approximately $3200 \mathrm{lb}$ of powder, followed by evacuation and sealing of the fill tubes. HIP parameters were selected based upon previous experience and verified by an experiment in which samples of Udimet 720 powder were exposed at HIP

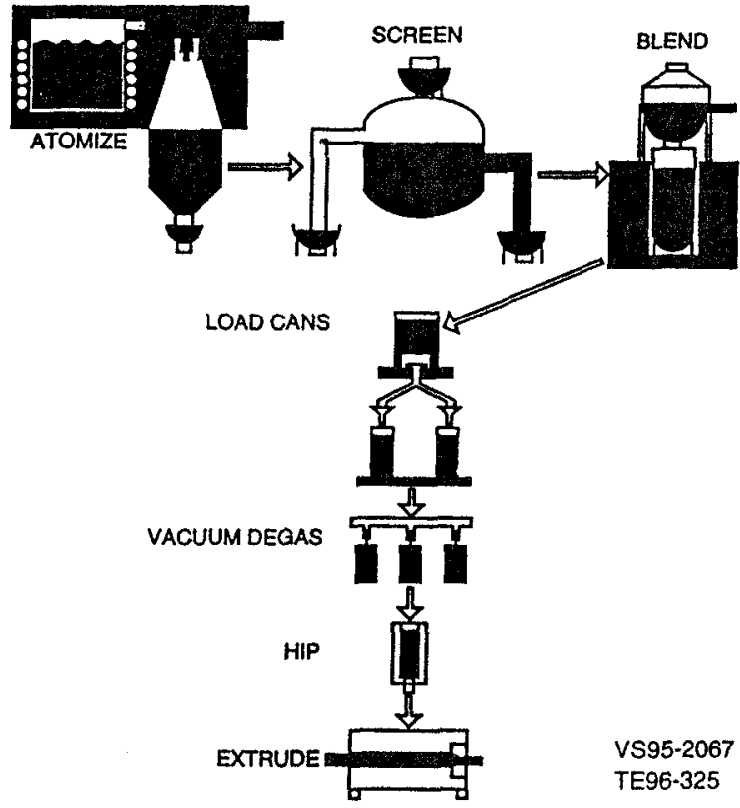

Figure 1: Process for producing HIP/extruded P/M billet.

temperatures of $2010^{\circ} \mathrm{F}, 2050^{\circ} \mathrm{F}$ and $2100^{\circ} \mathrm{F}$. As expected, all samples exhibited full consolidation. The HIP cycle selected for the fullscale billets was based upon selection of a commercially common HIP cycle for economic considerations. A thermally induced porosity (TIP) test of the consolidated powder billet showed a density loss of less that $0.3 \%$ at $2200^{\circ} \mathrm{F} / 4 \mathrm{hr}$.

\section{Extrusion}

The extrusion processing was performed in a 12,000 ton extrusion press at IXP (formerly Curtiss-Wright Corporation). The HIPed billet preforms were pushed through a $10.25 \mathrm{in}$. diameter die. The extruded billet was turned to $9.3 \mathrm{in}$. diameter, inspected and cut to individual forging mults. The as-extruded microstructure displayed a uniform fully hot-worked grain structure with grain size of ASTM 12. Ultrasonic inspectability of the billet was excellent, with no indications above the $30 \%$ of a No.1 flat bottom hole (FBH) limit. This shows the superiority of $\mathrm{P} / \mathrm{M}$ material with regard to the ultrasonic inspectability of cast/wrought Udimet 720 billet which has a $100 \%$ of a No. 2 FBH minimum limit.

Table I Nominal Compositions by Wt \% of High Strength Turbine Disk Alloys

\begin{tabular}{|l|c|c|c|c|c|c|c|c|c|c|c|c|}
\hline \multicolumn{1}{|c|}{ Alloy } & Form & $\mathrm{C}$ & $\mathrm{B}$ & $\mathrm{Cr}$ & $\mathrm{Co}$ & $\mathrm{Mo}$ & $\mathrm{W}$ & $\mathrm{Ti}$ & $\mathrm{Al}$ & $\mathrm{Zr}$ & Other & $\mathrm{Ni}$ \\
\hline U720 & $\mathrm{P} / \mathrm{M}$ & 0.025 & 0.020 & 16.0 & 14.7 & 3.0 & 1.25 & 5.0 & 2.5 & 0.03 & - & $\mathrm{Bal}$ \\
U720 & $\mathrm{W}$ & 0.035 & 0.033 & 18.0 & 14.7 & 3.0 & 1.25 & 5.0 & 2.5 & 0.03 & - & $\mathrm{Bal}$ \\
U720 MC & $\mathrm{W}$ & 0.015 & 0.017 & 16.0 & 14.7 & 3.0 & 1.25 & 5.0 & 2.5 & 0.03 & - & $\mathrm{Bal}$ \\
Rene 95 & $\mathrm{P} / \mathrm{M}$ & 0.07 & 0.010 & 13.0 & 8.0 & 3.5 & 3.5 & 2.5 & 3.5 & 0.05 & $3.5 \mathrm{Cb}$ & $\mathrm{Bal}$ \\
Astroloy & $\mathrm{P} / \mathrm{M}$ & 0.042 & 0.02 & 14.7 & 17.0 & 5.1 & - & 3.5 & 4.1 & - & - & $\mathrm{Bal}$ \\
N18 & $\mathrm{P} / \mathrm{M}$ & 0.020 & 0.015 & 11.5 & 15.5 & 6.5 & - & 4.3 & 4.3 & - & $0.5 \mathrm{Hf}$ & $\mathrm{Bal}$ \\
\hline
\end{tabular}

${ }^{*} \mathrm{P} / \mathrm{M}$ - powder metallurgy; W - wrought 


\section{PT2 Disk Forging Development}

\section{Forge Process}

The forging method utilized for the manufacture of the PT2 disks was a multi-disk duster design that was processed through a very controlled isothermal press forging operation. The cluster was designed to yield seven individual PT2 disks from each single large forging. This $1=7$ approach allowed usage of costeffective large diameter input billet stock and an extensive increase in production rates. In contrast, a conventional singlepiece forge method would require more costly smaller diameter billet input stock and one at a time forge processing.

A signature of the isothermal forging press method is the ability to forge to a near-net shape, with tight envelopes over the ultrasonic shape. The effective manufacture of the highly contoured PT2 disk to a near-net, nonaxisymmetric cluster configuration was a significant challenge. Extensive computer modeling was performed by Ladish to simulate metal flow and enable an efficient design of the forge tooling. Flow stress data for the $\mathrm{P} / \mathrm{M}$ Udimet 720 was used in the forging simulation model and identified a range of acceptable forging conditions. The flow stress data was found to be very comparable to conventional fine grain cast/wrought Udimet 720 .

Subscale dies were first produced to validate the aggresive nearnet shaped tool design, to confirm acceptable metal flow and complete die fill, and to validate the $\mathrm{P} / \mathrm{M}$ Udimet 720 material which was produced by the novel processing route. Following successful validation with subscale forgings, full-scale tooling was manufactured and PI2 cluster forgings over 26 inches in diameter were successfully produced, as typified by the forging in Figure 2

To prepare for an effective and uniform heat treatment, each large fullscale forging was excised to produce seven individual disks.

\section{Heat Treat Selection}

The current heat treat approach for fine grain Udimet 720 is a subsolvus solution followed by a two-step age. An empirical

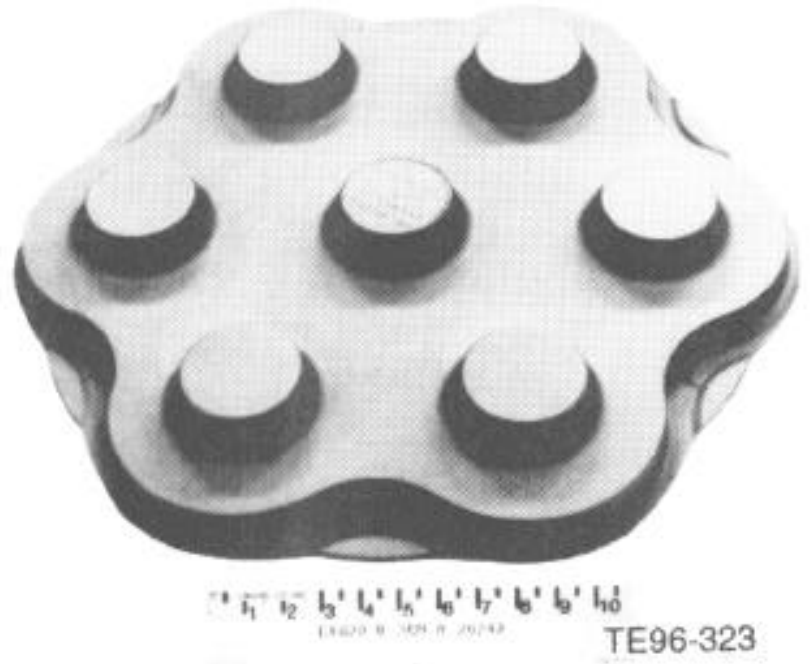

Figure 2: P/M Udimet 720 isothermal cluster forging. study was made to evaluate the effect of cooling rate on mechanical properties. Cooling rate was controlled by disk geometry (solid or bored) and quench medium (oil or air). Test disks were drilled and instrumented with thermocouples to determine cooling rate during quenching for each of the conditions. To correlate cooling rate with mecharical properties, tensile and creep tests were performed for each condition. As shown in Figure 3 , the highest cooling rate, which was produced by oil quenching a bored disk, produced the highest tensile properties. Ductilities for all strength levels were excellent. Based on this study, a heat treat practice was selected and implemented for the PT2 disk forgings.

\section{Evaluation of Forgings}

\section{Microstructure}

Selected disks were sectioned at various locations and evaluated for microstructural uniformity. Because of the design of this particular cluster forging, the metal flow characteristics during forging are nonaxisymetric for six of the seven disks. Only the center disk of this cluster forging experiences true axisymetric metal flow during the forging operation. To determine whether this presents any microstnuctural variation, samples were taken

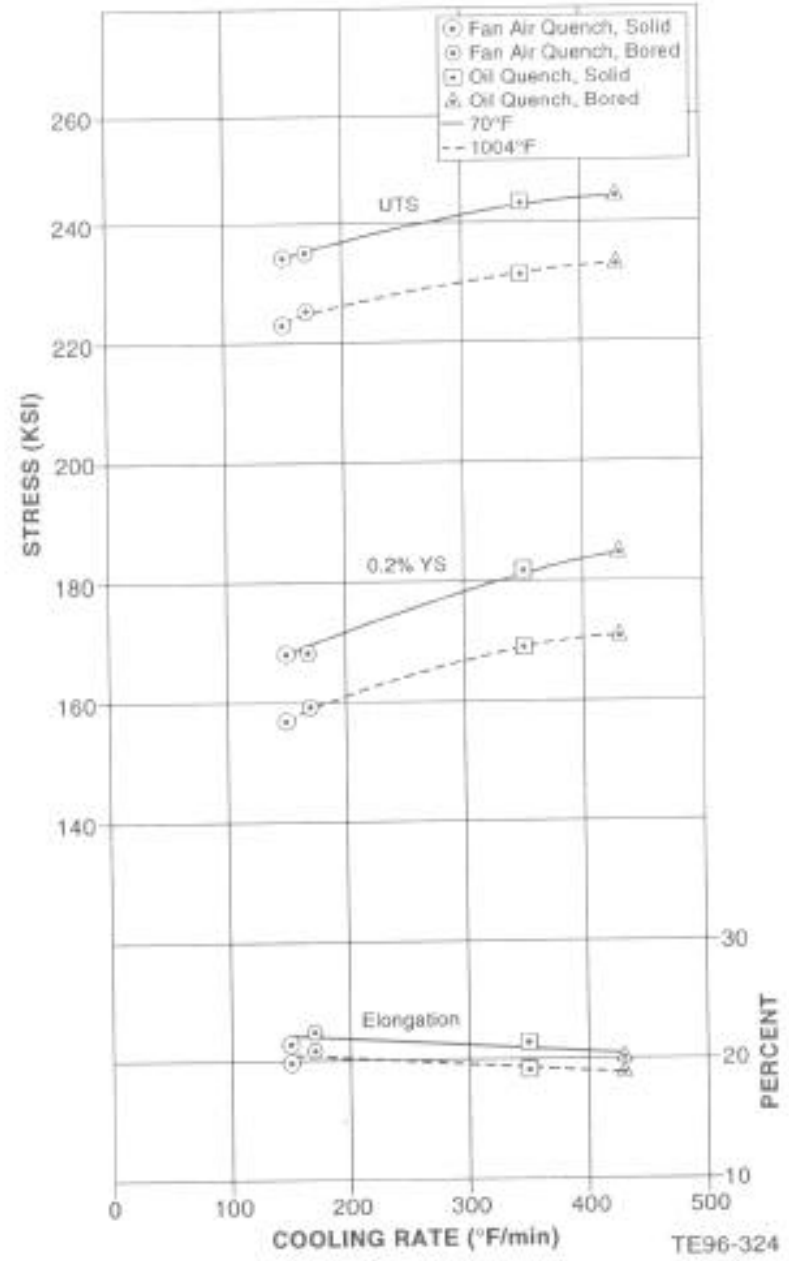

Figure 3: Effect of cooling rate from $2000^{\circ} \mathrm{F} / 2 \mathrm{hr}$ on $\mathrm{P} / \mathrm{M}$ Udimet 720 tensile properties. 
from various areas of cluster forgings. As shown in the photomicrographs in Figure 4, the microstructure displays an extremely uniform ASTM 12-14 grain size. The microstructure exhibits well distributed primary gamma prime with no evidence of a prior powder particle boundary structure. A higher magnification SEM photomicrograph, Figure 5, shows a high percentage of primary gamma prime and grain boundaries with discrete carbide and boride particles. No effect of location within the cluster forging can be detected in the microstructure, attesting to the extreme uniformity of the isothermal forging method.

\section{Material Properties}

An extensive material property characterization was conducted on specimens removed from representative disks processed to the final heat treatment schedule. Testing included tensile, creep/ rupture, smooth- and notched-bar LCF, and fatigue crack growth rate testing. A sampling of the test data is presented in the following paragraphs.

Tensile samples were removed from the chordal direction from the disks and tested over a temperature range of $70^{\circ} \mathrm{F}$ to $1600^{\circ} \mathrm{F}$. Ultimate tensile strength and $0.2 \%$ yield strength, shown in Fig ure 6 , demonstrate excellent strength characteristics competitive with other high strength disk alloys. Ductility was excellent over the entire temperature range that was tested.

Smooth bar LCF tests were conducted at $800^{\circ} \mathrm{F}, 1000^{\circ} \mathrm{F}$ and $1200^{\circ} \mathrm{F}$. Results of tests conducted at these temperatures at an Rratio $=0$, and frequency of $20 \mathrm{cpm}$ in strain control are summarized in Figure 7 for 30,000 ) cycles mean initiation life. P/M Udimet 720 displayed higher mean lives than cast/wrought Udimet 720 at all three temperatures. The difference in mean lives between materials decreases with increasing temperature due to creep/fatigue interaction with the finer grain microstructure observed in the $\mathrm{P} / \mathrm{M}$ Udimet 720 material. The data scatter was also better for the $\mathrm{P} / \mathrm{M}$ material at $800^{\circ} \mathrm{F}$ and $1000^{\circ} \mathrm{F}$, and only slightly higher at $1200^{\circ} \mathrm{F}$ than the cast/wrought material.

Fracture surfaces of LCF specimens were examined to assess the characteristics of the initiation site. Failures typically initiated from features shown in Figure 8, which are typical of most other argon atomized $\mathrm{P} / \mathrm{M}$ superalloys. The predominant initiation features were microporosity formed by entrapped argon and grain boundary facets. Fewer than $30 \%$ of the specimens failed at nonmetallic inclusions. The inclusions were of two general types: discrete particles of zirconia and agglomerated particles of alumina, silica and titanium oxide. An analysis of the LCF data indicated that nonmetallic inclusions did not seem to adversely affect the overall behavior of the LCF specimens.

Fatigue crack growth rate testing was performed in air at $800^{\circ} \mathrm{F}$ and $1200^{\circ} \mathrm{F}$ using a frequency of $10 \mathrm{~Hz}$ and a triangular loading wave form. The results at $800^{\circ} \mathrm{F}$, Figure 9 , show equivalence with cast/wrought Udimet 720 , a material which has demonstrated excellent damage tolerance characteristics (Ref. 2). The data shows a general trend of slightly lower crack growth rates at low stress intensity factors and higher crack growth rates at the higher stress intensity lactors relative to the cast/wrought Udimet 720 . The differences in crack growth rates are likely explained again by the finer grain size demonstrated by the $\mathrm{P} / \mathrm{M}$ Udimet 720 microstructure. Dwell time tests were performed at $1200^{\circ} \mathrm{F}$ with a 5-minute hold at maximum stress. The effect of five minute dwell time on crack growth rate was measured to be

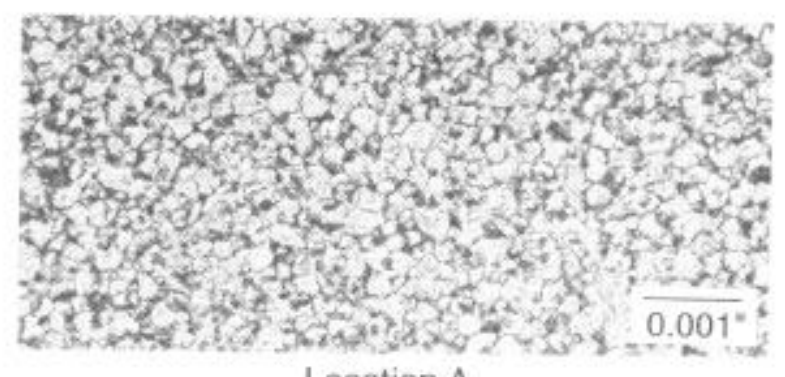

Location A
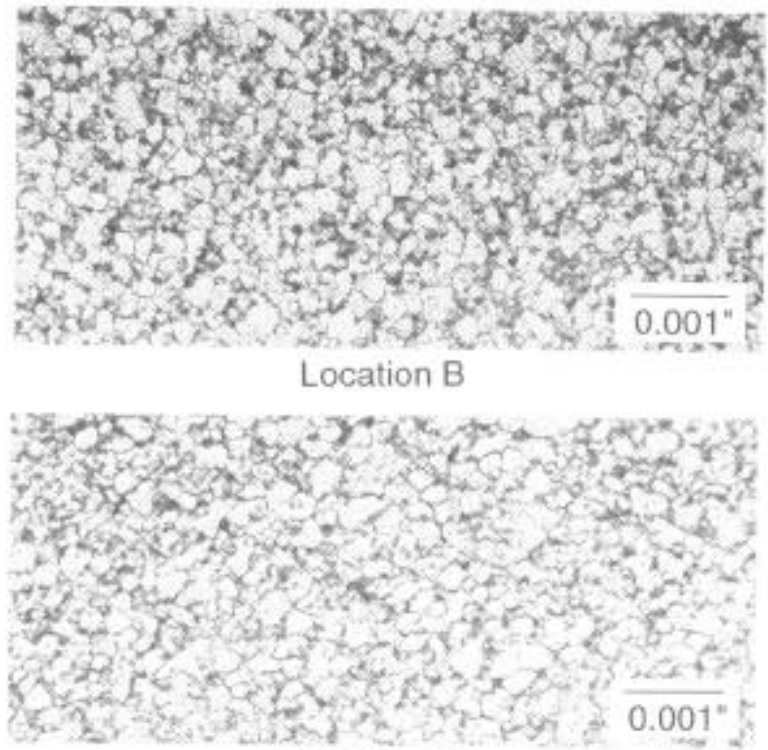

Location C
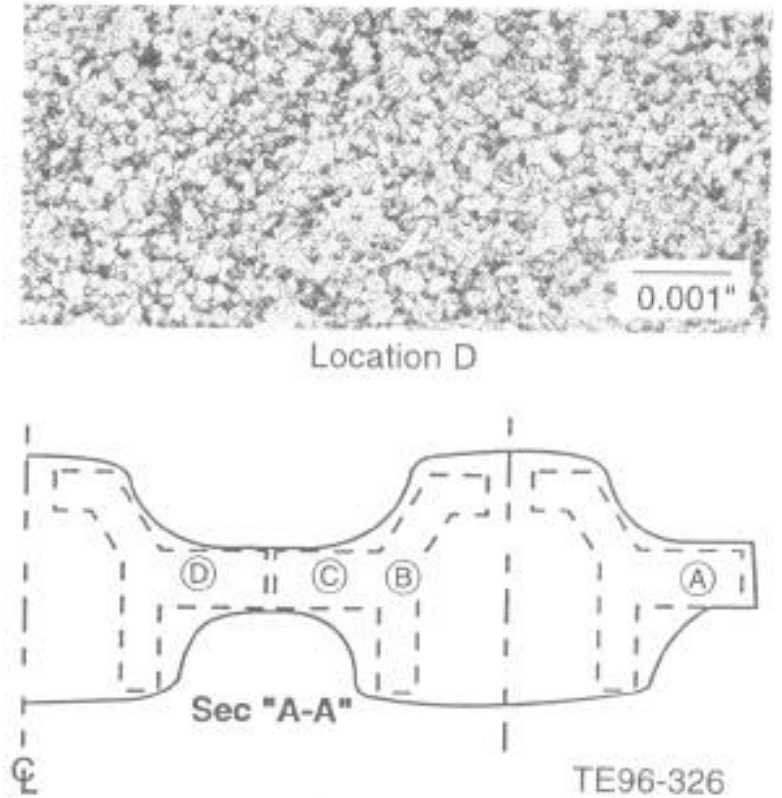

Figure 4: Microstructure of $\mathrm{P} / \mathrm{M}$ Udimet 720 forging at various locations. 


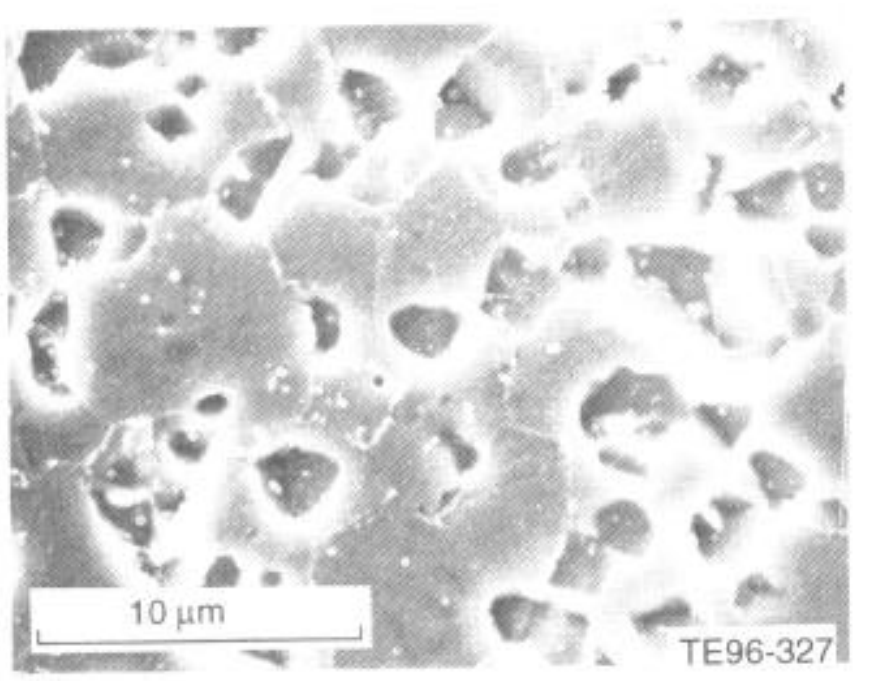

Figure 5: SEM photomicrograph of $\mathrm{P} / \mathrm{M}$ Udimet 720 microstructure showing primary gamma prime (etched) and distribution of fine carbide and boride particles located primarily in grain boundaries.

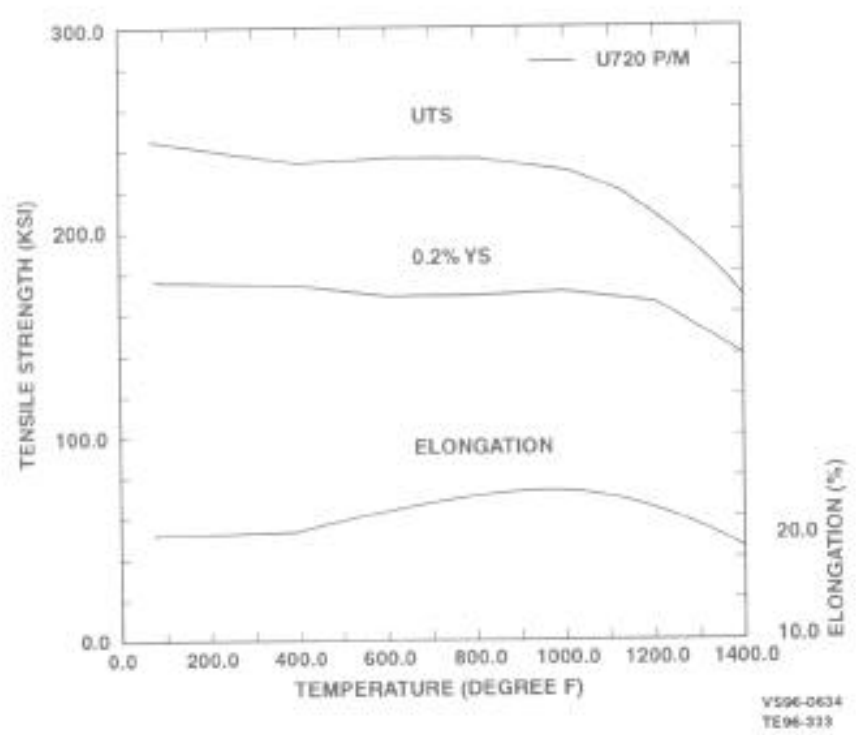

Figure 6: Tensile properties of P/M Udimet 720 .

an order of magnitude acceleration in crack growth rate as compared with the cyclic-dependent test conditions (Ret. 5). This phenomenon is typical of high strength superalloys which demonstrate grain sizes in the size range of the P/M Udimet 720 represented in this work.

\section{Component Testing}

To qualify the $\mathrm{P} / \mathrm{M}$ Udimet 720 forgings for development engine testing, component tests were required by the U.S. Army to certify the material and certain aspects of the design. The required tests included a cyclic spin test and an overspeed burst test. Several forgings were fully machined to the PT2 disk configuration. The PT2 disk, Figure 10, features an integral stub shaft on the



Figure 7: Total strain for 30,000 cycles mean life for P/M Udimet 720.
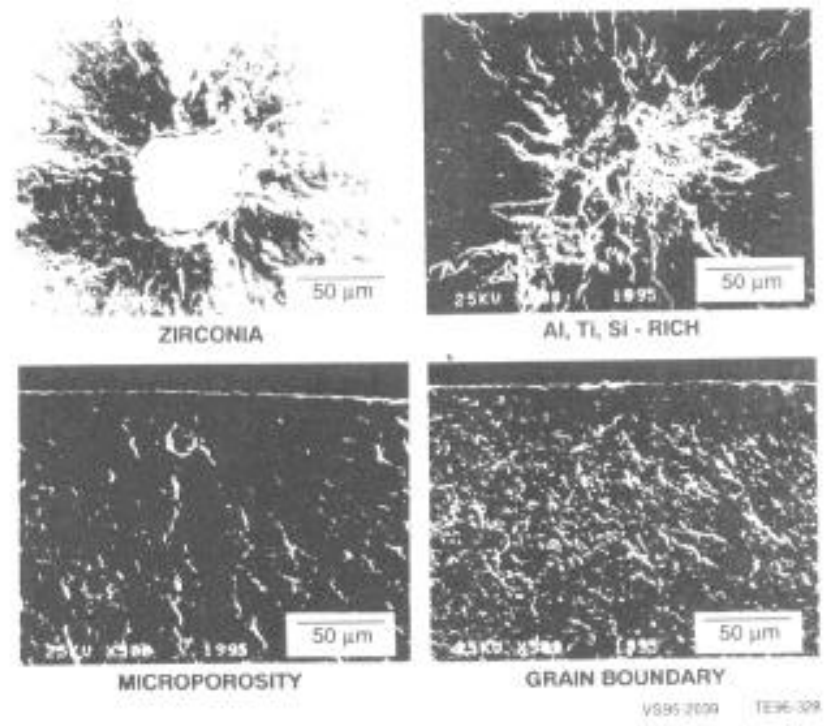

Figure 8: Typical low cycle fatigue initiation site features.

aft face which connects to the power turbine output shaft. Turbine blades are attached with a single lob dovetail attachment.

\section{Cydic Spin Test}

A fully-bladed wheel was utilized for the cyclic spin test which was conducted at $1010^{\circ} \mathrm{F}$ in an evacuated spin pit facility. The test cycle consisted of an excursion from idle speed to $23,375 \mathrm{rpm}$ $(105 \% \mathrm{~Np})$ and back to idle. Each test cycle was approximately 20 seconds in duration. The test was run in two 15,000 cycle segments, with a teardown inspection at the end of each cycle. The $\mathrm{P} / \mathrm{M}$ Udimet 720 disk displayed no cracking or other visible distress at the end of each test segment, successfully passing the cyclic life requirement. 




Figure 9: Fatigue crack growth rate comparison at $800^{\circ} \mathrm{F}$

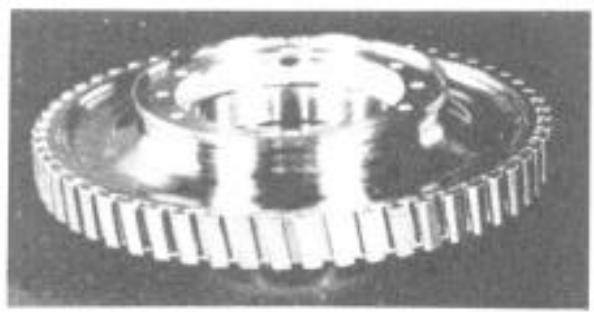

FORE

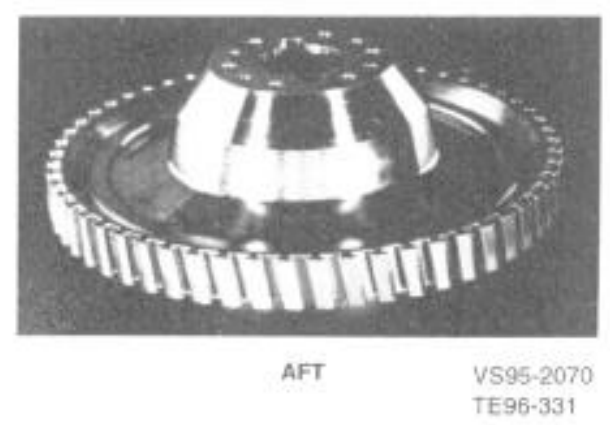

Figure 10: Fully machined T800 PT2 turbine disk made from $\mathrm{P} / \mathrm{M}$ Udimet 720 .

\section{Burst Test}

Overspeed capability is a significant feature of most power turbine designs. The T800 engine must demonstrate mechanical integrity at a minimum of $151 \% \mathrm{~Np}$ overspeed condition. The PT2 wheel is designed to intentionally fail in the blade rather than in the disk in an extreme overspeed situation. For this reason, the overspeed burst test was performed on a PT2 disk which was fitted with high strength "dummy" blades in place of the production cast turbine blades so as not to fail a blade before wheel burst. The disk used in the burst test was first spun to $34,848 \mathrm{rpm}(151 \% \mathrm{~Np}$ ) and held for five minutes to demonstrate minimum integrity speed. Following dimensional inspection, the disk was reinstalled in the spin pit and accelerated to burst. Disk burst occurred at $36,875 \mathrm{rpm}(160 \% \mathrm{~Np})$. The disk fragments were reassembled after the test and examined for fracture characteristics. Failure analysis indicated that the fracture initiated in the forward flange area near the bore and propagated through the web and into the rim. No metallurgical anomalies were found in the fracture initiation site. This test demonstrated adequate burst margin for the P/M Udimet 720 material and cleared the Army requirements for subsequent engine testing.

\section{Cast Analysis}

The primary goal of this effort was to achieve cost savings on the order of $20 \%$ over the current disk produced by hot-die forging of cast/wrought Udimet 720 . To assess relative costs, estimates were obtained for the bill-of-material forgings and compared with cost projections for the cluster forged P/M Udimet 720 forgings. A comparison of costs are shown in Figure 11 for both T800 power turbine disk configurations. The cost savings for the $\mathrm{P} / \mathrm{M}$ Udimet 720 disks exceeded the goals by significant amounts for lot sizes representing minimum production quantities. These savings could have a significant impact on expenditures over the entire life of the T800 production program.

\section{Summary}

$\mathrm{P} / \mathrm{M}$ Udimet 720 has proven to be a viable, cost-effective material for use in highly stressed turbine disk applications. An approach for producing billet by the HIP/extrude process was identified which is shown to be very competitive with conventional cast/ wrought Udimet 720 billet on a cost basis. The development of an aggressive geometry isothermal cluster forging was key in the approach to utilize cost-effective large diameter fine grain $\mathrm{P} / \mathrm{M}$ billet for the production of small turbine disks. The individual disks excised from the cluster forging prove to be uniform in microstructure and mechanical properties, irrespective of orientation within the larger cluster forging. The mechanical prop: erties demonstrated by $\mathrm{P} / \mathrm{M}$ Udimet 720 in general meet or exceed the properties of the cast/wrought version of that alloy and are competitive with other contemporary $\mathrm{P} / \mathrm{M}$ superalloys. The fatigue crack growth properties of $\mathrm{P} / \mathrm{M}$ Udimet 720 demonstrate good crack growth resistance over a broad temperature range. However, fatigue crack growth could benefit from additional improvement in the area of high temperature $\left(1200^{\circ} \mathrm{F}\right)$ dwell time. The P/M Udimet 720 properties meet the design criteria for the burst-limited PT2 turbine disk and representative disks have surpassed component test requirements established for continued T800 development engine testing. Cost projections obtained for isothermally cluster-forged $\mathrm{P} / \mathrm{M}$ Udimet $720 \mathrm{PT} 2$ disks indicate that a potential $25-30 \%$ cost savings can be achieved for production-size lots. 


\section{References}

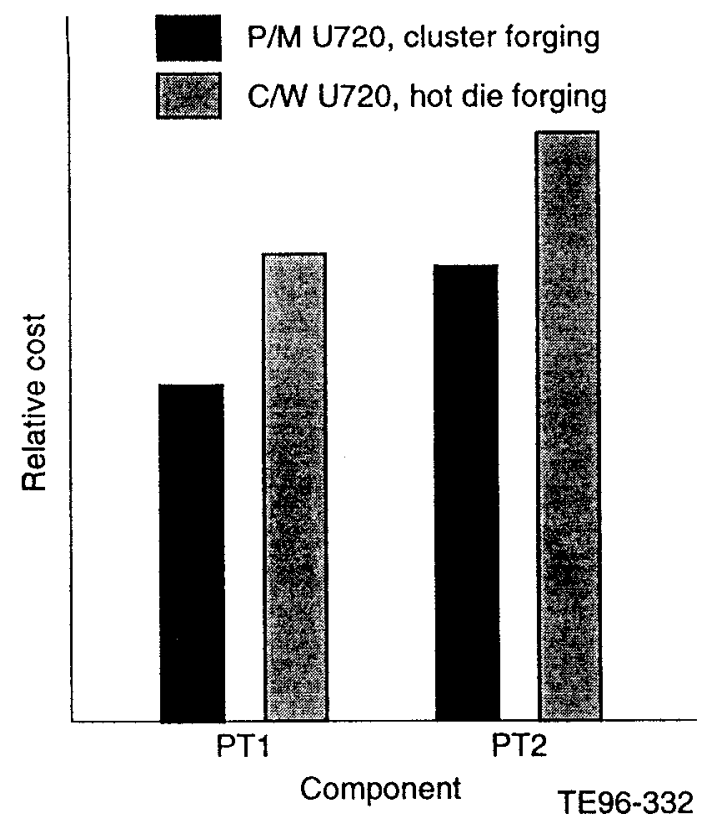

Figure 11: Comparison of cost estimates.

\section{Acknowledgements}

The authors wish to thank the U.S. Army Aviation and Troop Command (ATCOM), Messrs. N. Singh and S. Nahal, for permission to publish the results of this effort. The efforts of the following Allison Engine Company employees are greatly appreciated: Dr. C. Yin for test monitoring, Messrs. T. Hensler and D. Pridemore for metallographic evaluations, and Messrs. R. Stusrud, B. Ewing and Dr. M. Thomas for their support and guidance. The efforts of Messrs. J. Blair and J. Buzzanell at Dynamet are greatly appreciated. Also contributing at the Ladish Company were Messrs. D. Furrer, D. Russell and Dr. R. Shankar.
1. F. E. Sczerzenie and G. E. Maurer, "Development of Udimet 720 for High Strength Disk Applications," Superalloys 1984 (Warrendale, PA; The Metallurgical Society, 1984), 573-582.

2. K. R. Bain et al., "Development of Damage Tolerant Microstructures in Udimet 720", Superalloys 1988 (Warrendale, PA; The Metallurgical Society, 1988), 13-22.

3. G. Kappler et al., "Conventionally Processed High Performance Disc Material for Advanced Aeroengine Design," published in the proceedings of the 4th European Propulsion Forum, 1993, Bath, U.K., pages 9.1-9.9.

4. D. R. Chang, D. D. Krueger, and R. A. Sprague, "Superalloy Powder Processing, Properties and Turbine Disk Applications," Superalloys 1984 (Warrendale, PA; The Metallurgical Society, 1984), 245-273.

5. C. Yin, "Materials Design Data Generation of LCF and FCGR for P/M Udimet 720 Alloy at Elevated Temperatures," (Report TDR AH1800-005, Allison Engine Company, 1995). 